\title{
Students in the Real-World of Performance Tasks Assessment: A Qualitative Inquiry
}

\author{
Marisa B. Petalla ${ }^{1}$ and Araceli C. Doromal ${ }^{2}$ \\ 1,2University of Negros Occidental-Recoletos, Bacolod City, Philippines
}

\section{Article history:}

Submitted: 6 February 2021

Revised: 28 February 2021

Accepted: 25 March 2021

\section{Keywords:}

Celebration of learning

Transfer of learning

Quality instruction

Performance assessment

Qualitative research

Philippines

ABSTRACT. Providing relevant learning activities in a responsive classroom is necessary to develop 21st-century skills and competencies among students. That is why performance task assessment comes in as part of the educational reform brought about by the $\mathrm{K}$ to 12 Curriculum of the Department of Education. Several studies on the challenges to the curriculum planners and educators in implementing the performance-based assessment have been conducted. However, limited research has been done to look into the challenges encountered by the students during this implementation. Thus, this study was conducted. Employing a generic qualitative research design, this study explores the challenges encountered by Senior High School students in the implementation of the performance task assessment. The data were gathered from the six participants who were chosen using criterion sampling, one of the purposeful sampling techniques. These participants got the lowest scores in the performance tasks component of the students' grades. The data were collected utilizing the unstructured interview. During the interview, the iterative process was followed until the saturation point was reached. The gathered data were analyzed using the recursive textual data analysis. The result of the study revealed that planning of tasks, execution of tasks, and consequences of tasks were contributory to the challenges encountered by students. Challenges on the planning of tasks included quality of leadership, preparation, and articulation. The absence of skills and lack of supervision and motivation were included in the challenges specific to the execution of tasks. Consequences of tasks included challenges brought about by unreliable scores received and the limited learning gained. The findings provided the baseline data for the formulation of departmental policies and procedures on the implementation of performance tasks assessment.

\subsection{Introduction}

For the longest time, teachers have depended on standardized tests for students' assessment. However, research revealed that these types of assessments do not often confirm what learners learn (Colley, 2008; Speers, 2008). Studies also highlighted that these traditional and conventional assessments are very narrow in scope and coverage. They do not measure the obtained deeper comprehension of a topic or the learned complex skills like problem-solving or critical thinking (Herrera et al., 2013). It is on everyone's awareness that an important element of real-world competence is applying knowledge and transferring knowledge and skills to real-world situations. This is where performance task assessment comes in as part of the educational reform brought about by the K to 12 Curriculum of the Department of Education (Zane, 2009).

Providing relevant learning activities in a responsive classroom is necessary to develop 21stcentury skills and competencies among students. Students must be given tasks and assessments that prepare their skills as part of the school's mandatory responsibility to promote a 21st-century classroom (Albay \& Eisma, 2021).

One assumption was that changes in assessment would improve higher-order thinking among students (Kuhn, 1991). The teachers also desired to design tasks that are not limited to evaluating knowledge and skills in isolation but would require students to transfer their knowledge in real-life situations. Researchers support this approach by advocating the revision of assessment practices to support instructional changes based on how students learn (O'Day \& Smith, 1993). Also, the tasks needed to be authentic, expecting students to demonstrate their thinking and eliciting a range of responses (Wiggins, 1993).

The authenticity of assessments is based on how they examine the student's knowledge and skills in a real-world context, prioritizing tasks rather than memorizing content and allowing students to practice, receive feedback on, and increase performance and products (Wiggins, 1998). With this goal in mind, authentic assessment is rapidly growing in the classroom in the country. This authentic assessment would develop "real world" skills and problem-solving (Newmann et al., 1995). 
In the Philippines, the implementation of the $\mathrm{K}$ to 12 Basic Education Program had created meaningful innovations in curricular activities, classroom instruction, and assessment practices. The Republic Act (RA) 10533 (2013), otherwise known as the Enhanced Basic Education Act of 2013, wanted that the curriculum shall apply constructivist, inquiry-based, reflective, collaborative, differentiated, and integrative pedagogical approaches. Performance task assessment is also highlighted to gauge and align students' learning and skills in performing practical tasks and dealing with real-life challenges (Republic Act No 10533, 2013). The increased emphasis on performancebased assessment aims to provide appropriate performance assessment to enable Filipino learners to successfully transfer their knowledge, understanding, and skills in future situations (Deped, 2015). Consequently, at the onset of this implementation, several challenges and difficulties were faced by the curriculum planners and implementers, teachers, and students.

Further, several studies have been conducted on the implementation of performance-based assessment (Hayati et al., 2017; Demir et al., 2019; Mustafa, 2012; Kristiawan \& Elnanda, 2017; Marc Chun, 2010; Barnes \& Urbankowski, 2014; Albay et al., 2021; VanTassel-Baska, Feng, \& Evans, 2007; Cargas, S., Williams, S., \& Rosenberg, M., 2017). However, limited research has been done currently to look into the students' challenges during the implementation (Linn, 1993; Kane \& Mitchell, 1996), and no qualitative study was conducted specifically on the challenges of students in the implementation of the performance task assessment. Thus, this study was conducted to fill in the gap in the literature.

This study intends to investigate the experiences of Senior High School students in the implementation of the Performance Tasks Assessment. Specifically, this study dwelt on the challenges the students encounter during the planning and performance of the tasks and the consequences of these performances. Further, the findings provided the baseline data for the formulation of departmental policies and procedures on the implementation of the performance tasks assessment.

\subsection{Methods}

Using a qualitative research design, this study utilized the generic qualitative research approach (Litchman, 2013) to search for the challenges encountered by Senior High School students in the implementation of the performance task assessment. A generic qualitative approach is described by Caelli et al. (2003), cited in Merriam (1988), as studies that explore and understand a phenomenon, a process, or the viewpoints and perspectives of the people concerned.

The data were collected from the six participants who were chosen using criterion sampling, one of the purposeful sampling techniques. The chosen participants were coded as Participant 1, Participant 2, and so on to ensure their anonymity. These participants got the lowest scores in the performance tasks component of the students' grades. An unstructured interview was utilized to gather the needed data. Creswell et al. (2003), cited in Petalla and Madrigal (2017), suggested conducting an in-depth interview with 3 to 10 individuals. They explained that the relevant point is the description of the meaning of a small number of individuals who have experienced the phenomenon. During the interview, the iterative process was followed until the saturation point was reached. The process required recursive textual data analysis, including organization, classification, categorization, search for patterns, and synthesis in culling out the transcribed interviews' insights. Litchman's (2013) 3 C's-coding, categorizing, and identifying concepts were employed to aid the researcher to obtain an in-depth and holistic comprehension of the phenomena.

\subsection{Results}

The paper aims to explore the experiences of the students in the implementation of the performance task assessment. To present an organized discussion, this section will be divided into the challenges encountered by students in planning tasks, the execution of tasks, and the consequences of tasks.

\section{Planning of Tasks}

Understanding the challenges of students, the exploration should start from planning the task itself. All other aspects of the implementation of performance task assessment in the classroom started with how the students plan and prepare for the assigned tasks required by the teacher. 
Difficult Execution of Task Comes with Unequipped Leaders. The participants' accounts revealed their insights on the difficulty of the execution of tasks, which is very much dependent on the quality of leaders leading the group. Good leadership comes with good communication skills, decisionmaking capability, creativity, knowledge, and skills of the task on hand, and the ability to work with the group harmoniously. One of the participants emphasized the importance of good leadership in planning when he mentioned:

"I think what is important in planning is good leadership. There must be somebody to lead the group."(Participant 2)

Unplanned Presentations Come with Lack of Preparation. The participants' narratives demonstrated their insights on the challenges they encountered in terms of the quality of their presentation brought about by the lack of preparation. Students were not given ample time to meet with the group, plan, and practice in preparation for their presentation. This was highlighted when one of the participants said:

"Sad thing is, the teacher assigns the task very late that we have to rush just to finish it.

Without careful planning and preparation, we cannot perform the task well." (Participant 4)

Unsubstantial Output Comes with Unarticulated Tasks. Undefined tasks, tasks not planned, and not well-prepared are just some of the things that added to the challenges that the students encountered. These kinds of tasks eat up most of the students' time, leading to neglecting other important things they are still to do. In one of the narratives of the participants, it emphasized the importance of clear and well-articulated task when she expressed:

"Maybe the problem is on how the teacher presented the task. It is always not clear to us.

Some teachers were not even prepared for the task they will require from us and just decide right there and then." (Participant 6)

\section{Execution of Tasks}

Exploring further the challenges of students, it should also look into the completion of the task. Based on the narratives of the participants, a unifying theme is on how the participants executed the task with the needed skills, supervision, and motivation.

Low Performances Come with the Absence of Skills. The narratives of the participants articulated their insights on the importance of proper scaffolding before the performance tasks. The development of the needed skills for the task is very significant for better performance. Teachers must begin by presenting the steps, processes, or strategies to students preparing them to perform independently. As explained by one participant, skills are pre-requisites of every task:

"It can be easier for us if our teacher prepares our skills for the task. Performance tasks are always complicated that sometimes we do not know what to do or how to do it." (Participant 1)

Poor Performances Come with Lack of Supervision. The quality of performance is dependent on the quality of time the teacher spent with the students. The teachers' presence would provide them the opportunity to assess students' progress. However, it will also encourage students' engagement in the activity and comply with the required tasks. As one of the participants explained:

"Teachers must properly manage the time and if they can remind the teachers from time to time on the progress of the task preparation. Without those reminders, students tend to also forget the task on hand. The progress report can also be solicited from us." (Participant 6)

Uninspired Students Come with Unmotivated Teachers. A motivated teacher is vital in inspiring students to achieve what is there to achieve in a certain task. It motivates them more than just to complete the task but inspires them to see what is beyond the more important task. The kind of environment the teacher is creating would inspire the students to achieve more. One participant explained the reason why teacher's motivation is a priority:

"We also need the motivation given to us by our teachers. If we see that teachers are motivated for the task and excited for the outcome, we are also motivated to make it to the best of our ability. We do not need pressure from the teachers because it will never help us." (Participant 5) 


\section{Consequences of Tasks}

One of the essential aspects to examine in understanding the challenges of the students is the end-product of the task- the amount of learning they gained represented by the scores they received. Participants revealed that the scores they got are as important as the learning they are expected to achieve.

Unreliable Scores Come with Undefined Criteria. The reliability of the scoring system is one of the students' challenges, as revealed in the participants' narratives. The quality of the rubrics and how the teacher made use of the rubrics are their concerns. Rubrics are supposed to assess students performance based on the objectives of the task, and the teacher, therefore, must give the score with objectivity. Notably, one of the participants' concern is on the reliability of the scores, claiming that: "We were also informed of how we will be graded by showing us the criteria and rubrics. However, I am not sure if the points given are fair since we also noticed that other groups are not doing their best in the performance, yet we were given the same score." (Participant 4)

Limited Learning Comes with the Absence of Understanding. The participants' accounts revealed their insights on the challenges they encountered in terms of the quality of learning from the performance task. They believe that quality learning goes with teachers' proper direction to students to appreciate and understand the activity. Thus, learning will surely take place. One of the participants stressed out the reason why they need to understand what is expected of them in doing the task:

"If this is something important to us, then we must be made aware of the reasons why. We will appreciate the task more if we understand the explanation of why we have this activity." (Participant 2)

\subsection{Discussion}

The results of the study revealed many significant insights. It was revealed in the participants' narratives that the quality of instruction performed by teachers is very significant in the quality of learning of students. The education profession, researchers, and policymakers all agree that teaching quality makes an important difference in students' learning, achievement, and life chances (CochranSmith, 2003). This sentiment is supported by a growing body of research, indicating that teacher quality is the most influential school-related factor influencing students' learning and achievement (Rice, 2003).

Further, providing students the opportunity to perform a task related to the real-world situation would facilitate the transfer of learning. Transfer of learning happens when experience or performance on one task influences the succeeding task (Ellis, 1965, cited in Rutherford-Hemming, 2012). Moreover, McKeachie (1987), cited in Rutherford-Hemming (2012), emphasized that a transfer of learning occurs if prior learning in a different situation is applied in the new situation.

Relative to the planning of the task, the narratives of the participants emphasized the importance of good leadership, enough preparation, and proper articulation. Without these, challenges arise. They revealed that they expect a lot from the leader of the group. They support the idea that leaders are often chosen for possessing excellent, task-relevant knowledge (Bass, 1990; Hollander, 1964; von Rueden et al., 2014); thus, they are very dependent on him. However, recent studies have shown that group members' personalities and attitudes are vital to leadership effectiveness. Without followers, leaders cannot lead. In any group task, followers are essential (Moore, 1976, cited in Olusegun, 1999). Therefore, group tasks must be more of a group effort.

The participants' narratives disclosed their claims that the quality of their performance depends on the quality of their preparation. In the study of Alford and Shrewsbury (2013), it was perceived that the difficulty of the preparation and the time in making the preparation might influence student performance. This is evident in the kinds of performance the students have when the time for preparation is neglected.

As shown in the participants' accounts, they considered the articulation of task affects output quality. This insight was supported by the idea that the quality of a product is largely dependent on the processes used to develop and maintain it. If the processes are not adequate, the end product will often not meet the requirements (CERTIFICATION ENSURES QUALITY OUTPUT, 2006). If the task is undefined, it will only follow the quality of the output. 
As to the execution of the task, it is worth noting that skills, supervision, and motivation are the important things needed by the students to accomplish their tasks. The skills of students that affect their performance were revealed in the participant's narratives. They believe that they can perform better when they are prepared for it. Scaffolding is supposed to be a pre-requisite in all tasks to be given to students. It is important to prepare them before letting them work independently on the task on hand. The scaffolding concept originated from Vygotsky's concept of the zone of proximal development, which highlighted the significance of supervision and help from adults and more capable peers (Vygotsky, 1978). The teacher often provides guidance. As students achieve proficiency over the task, the teacher gradually decreases the frequency and amount of assistance until they can work individually and independently (Danli, 2017).

Furthermore, students believe that good classroom supervision practices lead to excellent performances of students. Classroom supervision involves the time the teacher spent with the students in preparing for the task. The closes the teacher supervises his students, the better the students achieve. It is supported by the idea that the best practices in teacher supervision and evaluation stress establish professional goals measured in terms of enhanced student learning (Feeney, 2007).

The narratives of the participants also uncovered their claims that teachers' motivation affects their performance in school. Also, the climate the teachers create in the classroom matters a lot to students. Teacher's involvement in giving students any kind of support is correlated with the demand for belongingness, care, and connection to others and is crucial to promoting students' motivation, engagement, and sense of belongingness (Juvonen, 2007; Kiefer et al., 2015).

Aside from exploring the preparation and execution of tasks, it is also important to give attention to the consequences of the performance task since this is the measurement of students' learning. This was disclosed in the accounts of the participants. The reliability of the scoring system is one of the students' challenges, as revealed in the participants' narrative. They express their doubt about how the teacher gives their grades despite the rubrics because they compare scores. This is also one of the aspects of implementing performance task assessment that is needed to be considered. In assessment methods such as case analysis, projects, portfolio, essays, where the answers given by students cannot be evaluated with full objectivity, rubrics are seen as a practical strategy for attaining solid and accurate evaluation of students' performances (Pellegrino et al., 1999, cited in Reddy, 2011). Thus, if rubrics are properly designed and presented to students, there will be no doubt about the quality of scores given to them.

Lastly, students should have a clear direction of where they should be going. They must be aware of what it is expected from them in all the activity they do in school. If the student does not appreciate the meaning of what he is learning, there is no need to strive on what he is expected to do in the class. Knowing precisely the purpose of what they are doing will improve their learning. There should be a practical meaning and direction for every class activity (Miño-Garcés, 2009). Instruction and assessment are more significant to students when they reflect or simulate problems, issues, or situations one might face in the world outside the classroom (Newmann, 1996).

\subsection{Conclusion}

The main purpose of having a performance task as part of the curriculum is to facilitate the transfer of learning. This goal will be achieved with careful planning, proper execution, and appropriate assessment of the task. It is evident in the result of the study that the quality of learning through performance tasks is dependent on the quality of attention given by the teachers in terms of classroom instruction, supervision, and direction to students. Further, the awareness of the end goal of the performance task is very significant for both the teacher and the students to facilitate the transfer of learning.

Therefore, the transfer of learning depends on how the tasks are carefully planned and implemented to suit the needs of the students in new situations. Students' application of their knowledge and skills into something meaningful to them can affect learning. Finally, by making the students overcome the challenges brought about by the implementation of the performance task in the classroom, they are given the opportunity to equip themselves with the needed skills in dealing with the future. Then, there is the transfer of learning.

To aid students in overcoming the challenges they encountered in the implementation of the performance task assessment, the following recommendations were suggested: (a) The curriculum 
planners must restudy the implementation of the performance task assessment by reviewing the program planning process-including students in the process, assessing accurately learners' perception of need and motivation to learn and identifying barriers and challenges to improve the program, (b) the school administrators have to give priorities to faculty development in terms of the implementation of performance task assessment. They must equip teachers with knowledge and skills on how to go about the assessment to answer the challenges encountered by the students in school so that they will be prepared not only for their college years but also for the world of work, (c) teachers must spend enough time planning for the task to be given to students. Their supervision and support must always be visible to students. Well- prepared rubrics must also be considered to be presented to students after assigning the task for them to be guided properly and to lessen their doubts on the quality of score they got, and (d) researchers must conduct more comprehensive research on the challenges encountered both by teachers and students in implementing the performance task assessment to cull out more insights for the improvement of the school's assessment program.

\section{REFERENCES}

Albay, E. M. \& Eisma, D. V. (2021). Performance task assessment supported by the design thinking process: Results from a true experimental research. Social Sciences \& Humanities Open, Volume 3, Issue 1, 2021, 100116

Alford, E. L., Pharm, D., \& Shrewsbury, R. P., Ph.D. (2013). Impact of required versus optional remake of preparation on pharmacy students' compounding accuracy. American Journal of Pharmaceutical Education, 77(4), 73. doi:http://dx.doi.org/10.5688/ajpe77473

Amrein, A. \& Berliner, D. (2002). High-stakes testing, uncertainty, and student learning. Education Policy Analysis Archives, 10(18), 1-69.

Barnes, N. C. \& Urbankowski, D. (2014) Planning, Implementing, and Assessing an Authentic Performance Task in Middle Grades Classrooms. Middle School Journal, 45:5, 1724, DOI: 10.1080/00940771.2014.11461896

Bass, B.M. (1990). Bas and Stogdilis handbook of leadership: Theory, research, and managerial applications ( $3^{\text {rd }}$ ed.). New York: Free Press.

Caelli, K., Ray, L., \& Mill, J. (2003). 'Clear as mud': Toward greater clarity in generic qualitative research. International Journal of Qualitative Methods, 2(2).

Cargas, S., Williams, S., \& Rosenberg, M. (2017). An approach to teaching critical thinking across disciplines using performance tasks with a common rubric, Thinking Skills and Creativity, Volume 26, 2017, Pages 24-37, ISSN 1871-1871, https://doi.org/10.1016/j.tsc.2017.05.005.

CERTIFICATION ENSURES QUALITY OUTPUT. (2006). US Fed News Service, Including US State News, Retrieved from https://search.proquest.com/docview/473206144? accountid=34542

Cochran-Smith, M. (2003). Teaching quality mailers. Journal of Teacher Education, 54, 95-98.

Creswell, J. W., Plano-Clark, V.L., Gutman, M.L., \& Hanson, W.E. (2003). Advanced mixed methods research designs. In A. Tashakkori \& C. Teddlie (Eds.), Handbook of mixed methods in social and behavioral research (pp.209-240). Thousand Oaks, CA: Sage.

Colley, K. (2008). Performance-based assessment. Science Teacher, 75(8), 68-72.

Danli, L. (2017). Autonomy in scaffolding as learning in teacher-student negotiation of meaning in a university EFL classroom. Chinese Journal of Applied Linguistics, 40(4), 410-430. doi:http:// dx.doi.org/10.1515/cjal-2017-0024

Demir, M., Tananis, C. A., \& Trahan, K. W. (2019). Evaluation of alternative assessment methods used in elementary schools. Egitim Ve Bilim, 44(197) Retrieved from https://search.proquest.com/ docview/2186795440?accountid $=34542$.

DepEd Order 8, series of 2015. Policy Guidelines on Classroom Assessment for the Kto12 Basic Education Program. www.deped.gov.ph/2015

Ellis H. C. (1965). The transfer of learning. New York, NY: Macmillan.

Hayati, A., Bentri, A., \& Rahmi, U. (2017). Analyzing the issues in the implementation of authentic assessment in the 2013 curriculum. Al-Ta'Lim Journal, 24(1), 53-59. doi:http://dx.doi. org/10.15548/jt.v24i1.256

Herrera, S., Cabral, R., \& Murry, K. (2013). Assessment accommodations for classroom teachers of culturally and linguistically diverse students (2nd ed.). Boston, MA: Allyn \& Bacon. 
Hollander, E. (1964). Leaders, groups, and influence. Oxford: Oxford University Press.

Holloway, I. (2005).Qualitative research in health care. Maidenhead, UK: Open University Press.

Kane, M.B. \& Mitchell, R. (1996). Implementing Performance Assessment: Promises, Problems, and Challenges. Mahwah, New Jersey: Laurence Erlbaum Associates, Inc., 1996.

Kuhn, pp. 71-78. Washington, D.C.: American Association for the Advancement of the Sciences, 1991.

Feeney, E. J. (2007). Quality feedback: The essential ingredient for teacher success. The Clearing House, 80(4), 191-197. Retrieved from https://search.proquest.com/ docview/196844471?accountid $=34542$

Fred M. Newmann and associates. (1996). Authentic Achievement- Restructuring Schools for Intellectual Quality. San Francisco: Jossey-Bass.

Fred M. Newmann, Walter G. Secada, and Gary G. Wehlage, A Guide to Authentic Instruction and Assessment: Vision, Standards and Scoring (Madison, WI: Wisconsin Center for Education Research, 1995)

Juvonen, J. (2007). Reforming middle schools: Focus on continuity, social connectedness, and engagement. Educational Psychologist, 42, 197-208. doi:10.1080/00461520701621046

Kiefer, S. M., Alley, K. M., \& Ellerbrock, C. R. (2015). Teacher and peer support for young adolescents' motivation, engagement, and school belonging. RMLE Online, 38(8), 1-18. Retrieved from https://search.proquest.com/docview/1707736247?accountid=34542

Kristiawan, M., \& Elnanda, D. (2017). The implementation of authentic assessment in the cultural history of Islamic subjects. Al-Ta'Lim Journal, 24(3), 266. doi:http://dx.doi.org/10.15548/ jt.v24i3.345

Linn, R. L. (1993) Educational Assessment: Expanded Expectations and Challenges. Educational Evaluation and Policy Analysis. 1993;15(1):1-16. doi:10.3102/01623737015001001

Lichtman, M. (2013).Qualitative Research in Education, A User's Guide 3rd Edition. USA: Sage Publications, Inc.

Marc Chun (2010) Taking Teaching to (Performance) Task: Linking Pedagogical and Assessment Practices, Change: The Magazine of Higher Learning, 42:2, 2229, DOI: 10.1080/00091381003590795

McKeachie W J, (1987). Cognitive skills and their transfer: Discussion. International Journal of Educational Research, 11, 707--712. 10.1016/0883-0355(87)90010-3

Merriam, S.B. (1988). Case Study Research in Education: A Qualitative Approach. Jossey-Bass, San Francis-co.

Miño-Garcés, F. (2009). Learning for life, a structured and motivational process of knowledge construction in the Acquisition/learning of English as a foreign language in native Spanish speakers. International Journal of English Studies, 9(1), 81-89,136-137. doi:http://dx.doi. org/10.6018/ijes.9.1.90651

Moore, L.L. (1976, June). The FMI Dimensions of follower maturity. Group and Organization Studies, $1(2) \cdot 203-222$

Mustafa, Z. (2012). TEACHERS' ENCOUNTERED CHALLENGES IN THE ADOPTION OF TASKBASED LANGUAGE TEACHING IN MALAYSIAN CLASSROOMS. International Journal of Arts \& Sciences, 5(3), 269-279. Retrieved from https://search.proquest.com/ docview $/ 1284080673$ ? accountid $=34542$

O'Day, Jennifer A, and Marshall S. Smith. (1993). "Systemic School Reform and Educational Opportunity." In Designing Coherent Educational Policy: Improving the System, edited by Susan H. Fuhrman, pp. 250-311. San Francisco, Calif.: Jossey-Bass.

Olusegun, A. S. (1999). Leadership effectiveness and personality characteristics of group members. Journal of Leadership Studies, 5(3), 26-40. doi:http://dx.doi. org/10.1177/107179199900500303

Pellegrino, J.W., Baxter, G.P. and Glaser, R. (1999), "Addressing the two disciplines problem: linking theories of cognition and learning with assessment and instructional practice," Review of Research in Education, Vol. 24, pp. 307-53.

Petalla, M.B. \& Madrigal, D.V. (2017). Teaching Standards Competence and Efficiency Performance of Basic Education Teachers. Journal of Institutional Research South East Asia, Vol. 15 Issue 3, p60-72. 13p.

Republic Act No. 10533 (2013). Republic Act No 10533. https://www.officialgazette.gov. ph/2013/05/15/republic-act-no-10533/ (2013), Accessed 12th Feb 2020 
Rice, J.R. (2003). Teacher quality: Understanding the effectiveness of teacher attributes. Washington, DC: Economic Policy Institute.

Rutherford-Hemming, T. (2012). Learning in simulated environments: Effect on learning transfer and clinical skill acquisition in nurse practitioner students Journal of Nursing Education, 51(7), 403406. doi:http://dx.doi.org/10.3928/01484834-20120427-04

Ryan, A. M. \& Patrick, H. (2001). The classroom social environment and changes in adolescents' motivation and engagement during middle school. American Educational Research Journal, 38(2), 437-460. doi:10.3102/00028312038002437

Speers, J. (2008). Design and utilization of performance assessment by vocational educators (Doctoral dissertation). Retrieve d from ProQuest. (3323940). (accessed 25/05/2014).

Spiro, R. J., Feltovich, P. J., \& Coulson, R. L. (2007). Cognitive flexibility theory. Retrieved on March 1 , 2007, from http://tip.psychology.org/spiro.html

VanTassel-Baska J, Feng AX, \& Evans BL. (2007). Patterns of Identification and Performance Among Gifted Students Identified Through Performance Tasks: A Three-Year Analysis. Gifted Child Quarterly. 2007;51(3):218-231. doi:10.1177/0016986207302717

von Rueden, C., Gurven, M., Kaplan, H., \& Stieglitz, J. (2014). Leadership in an egalitarian society. Human Nature: An Interdisciplinary Biosocial Perspective, 25(4), 538-66. doi:http:// dx.doi.org/10.1007/s12110-014-9213-4

Vygotsky, L.S. (1978). Mind in society: The development of higher psychological processes. Cambridge: Harvard University Press.

Wiggins, Grant P. Assessing Student Performance: Exploring the Purpose and Limits of Testing. San Francisco, Calif:. Jossey-Bass, 1993.

Zane, T. W. (2009). Performance assessment design principles gleaned from constructivist learning theory (part 2). TechTrends, 53(3), 86-94. Retrieved from https://search.proquest.com/ docview/223115197?accountid=34542 (overall)

\section{Correspondence:}

Marisa B. Petalla

marshe112582@gmail.com

https://orcid.org/0000-0001-9332-4829

Araceli C. Doromal

araceli_doromal@yahoo.com

https://orcid.org/0000-0002-0589-5953 